\title{
Insights into Bee Evolution: A Tribute to Charles D. Michener
}

This is a very special year for bee research! On September 22, 2008, Professor Charles D. Michener will turn 90 years old. As hard as it is to quantify the scientific importance of a researcher, it does not seem too exaggerated to propose that Dr. Michener is the most important bee specialist of our time. From his first scientific paper on bees, published in 1935, the list of his publications in the last 73 years grew to include over 400 articles and books. More important than the sheer number of papers is their impact on the field of bee research. Dr. Michener's articles and books are classic references that encompass virtually all aspects of bee research: taxonomy and systematics, evolution of social behavior, biogeography, nesting biology, cleptoparasitism, various aspects of bee behavior and ecology, comparative morphology, pollination and floral relationships. Michener (2000, 2007a) is the bible of bee biology and systematics. Dr. Michener's productive career also included research on theoretical topics related to classification, systematics, and social evolution. Because it is not our intension here to review Dr. Michener's life and career, we recommend the reading of his fascinating personal account on his development as entomologist (Michener 2007b). This special issue of Apidologie is dedicated to him as a tribute to his contributions to the advancement of bee research.

Three of the thirteen papers are reviews of various aspects of bee biology. Simon Tierney and colleagues discuss the evolution of allodapine bees (Apidae: Xylocopinae) with an emphasis on social behavior and social parasitism (two of Dr. Michener's favorite subjects). Tierney et al. demonstrate how a robust phylogenetic hypothesis for Allodapini helps in understanding the evolution of parasitism, social evolution, and historical biogeography. Eduardo Almeida reviews the nesting biology of the family Colletidae in light of a new phylogenetic hypothesis. Finally, Jack Neff provides a thorough analysis of the components of nest provisioning behavior in solitary bees. He analyzes the relationship between female body size, pollen load size, trip duration and other aspects of provisioning. His review provides new insights into the costs and benefits of different modes of pollen transport in solitary bees.

A number of papers focus on phylogeny, systematics and taxonomy of bees. Williams and colleagues propose a revised classification for the bumble bees. Their paper provides a new standardized subgeneric classification for Bombus as well as a key to the newly circumscribed subgenera. Two empirical studies (Almeida and co-authors and Danforth and co-authors) provide analyses of phylogenetic relationships using DNA sequence data in colletid and halictid bees, respectively. Almeida and co-authors establish phylogenetic relationships in the poorly studied colletid subfamily Xeromelissinae. Danforth et al. present a review of various aspects of halictid biology and produce a molecular phylogeny for the subfamily Halictinae that includes relatively complete sampling of the endemic African genera and subgenera.

Five studies employ phylogenetic information to examine the evolution of important biological traits in bees, including nesting biology, sociality, mating behavior and floral associations. Rasmussen and Camargo examine the evolution of nest architecture in the Neotropical stingless bee genus Trigona. By mapping characters that describe the diversity of nesting onto a phylogenetic framework, the authors find that some nest architectural characters have a significant phylogenetic signal. Likewise, Leys and Hogendoorn apply comparative methods to better understand the evolution of mating behavior in large carpenter bees (Apidae: Xyocopinae: Xylocopa). Two studies (Larkin and co-authors and Michez and co-authors) analyze the evolution of host-plant associations in bees (Andrenidae and Melittidae, respectively) by mapping diet 
breadth and host-plant associations onto phylogenetic trees based on molecular and morphological data. Their studies provide important new insights into the patterns of host-plant evolution in oligolectic bees. Finally, Kawakita and collaborators present the largest bee molecular dataset to date for resolving the phylogeny of the corbiculate tribes (the orchid bees, stingless bees, bumblebees and honey bees). Their results corroborate earlier molecular studies and provide a robustly supported topology that implies dual origins of advanced eusociality: ((Apini+Euglossini $)+($ Meliponini+Bombini)). The authors present a comprehensive discussion of the persistent incongruence between morphological and molecular results, and suggest new directions for resolving the conflicting results.

Two final papers present new data on bee faunistics (Minckley) and the nesting and social behavior of African halictine bees (Timmermann \& Kuhlmann). Minckley compares the bee fauna of two regions of North America (one mesic and one xeric) in order to understand patterns of oligolecty, social behavior, and parasitism across different localities and habitat types. Timmermann and Kuhlmann describe the nesting biology and floral associations of a species of the poorly known African genus Patellapis. This is the first description of nesting biology, social behavior and floral choice in this fascinating group.

One of the goals of any student of bee evolution is to find something that Charles Michener did not already know. Bee biologists are often confronted with the frustrating reality that "Mich already said that." We hope that at least a few of the results obtained by the authors of these papers will provide Dr. Michener with some surprises.

Bryan N. Danforth

Eduardo A.B. Almeida

December 2007

\section{REFERENCES}

Michener C.D. (2000) The Bees of the World, 1st Ed., John Hopkins University Press, Baltimore.

Michener C.D. (2007a) The Bees of the World, 2nd Ed., John Hopkins University Press, Baltimore.

Michener C.D. (2007b) The professional development of an entomologist, Annu. Rev. Entomol. 52, 1-15. 